\title{
Establishment of Embryonic Stem Cells and Generation of Genetically Modified Rats
}

\author{
Masaki Kawamata and Takahiro Ochiya \\ National Cancer Center Research Institute, Tokyo \\ Japan
}

\section{Introduction}

Authentic embryonic stem (ES) cells are derived from the inner cell mass (ICM) of preimplantation blastocysts in rodents. ES cells have been routinely derived since 1981 (Evans \& Kaufman, 1981; Martin, 1981). They are capable of generating germline chimeras following injection into blastocysts. A very large number of knockin/knockout mice have been produced so far, leading to significant progress in both basic research and clinical investigation. However, recent reports indicate that the phenotypes of knockout mice sometimes do not correspond to human diseases (Rogers et al., 2008). Thus, the ES cells of other species, especially rats, have been desired for the generation of new animal models for human diseases.

In 2008, we successfully established rat ES cells with a chimeric contribution (Ueda et al., 2008). Soon after our report, authentic rat ES cells that could complete a germline transmission were established (Buehr et al., 2008; Li et al., 2008). These reports suggest that a removal of serum from a culture medium is necessary for maintaining the pluripotency of rat ES cells (Kawamata \& Ochiya, 2010a). However, despite the assertion in these reports, we recently established high-quality rat ES cells by using a combination of $20 \%$ serum and signaling inhibitors. Furthermore, this culture condition enabled the ES cells to receive gene manipulation, leading to obtaining genetically modified rats via germline transmission. We also discovered an indispensable technique during a blastocyst injection process for the generation of germline chimeras (Kawamata \& Ochiya, 2010b).

This new technology should provide valuable animal models for the study of human diseases by the induction of gene-targeting manipulations in the rat ES cells. In this chapter, we discuss the techniques for the establishment of rat ES cells compared to mouse ES cells and the creation of genetically modified rats.

\section{Mouse ES cells}

ES cells are derived from the inner cell mass (ICM) of blastocysts and are capable of unlimited, undifferentiated proliferation in vitro. Mouse ES cell lines were first established by culturing ICM (Evans \& Kaufman, 1981; Martin, 1981) in the presence of serum and a feeder cell layer made of mouse embryonic fibroblast (MEF). Later, it was shown that the leukemia inhibitory factor (LIF) is the key cytokine secreted by feeders to support mouse ES cell self-renewal and that LIF was able to replace the requirement for feeders in propagation (Smith et al., 1988; Williams et al., 1988). These cells have a stable developmental potential to 
form derivatives of all three embryonic germ layers even after prolonged culture (Thomson \& Marshall, 1998) and have been used to study the mechanism of cell differentiation. Moreover, they are capable of generating germ-line chimeras following injection into the blastocyst (Bradley et al., 1984). Thus, the creation of targeted mutation in the mouse has been a valuable source of animal models of human disease.

In 2003, Ying et al. demonstrated that bone morphogenetic proteins (BMPs) could replace serum and act together with LIF to maintain mouse ES cell self-renewal (Ying et al., 2003). Furthermore, in 2008, they found that a combination of mitogen-activated protein kinase kinase (MEK) inhibitor PD0325901 and glycogen synthase kinase-3 (GSK3) inhibitor CHIR99021, termed 2i, could replace serum, MEF, and LIF in mouse ES cells (Ying et al., 2008). Under this condition, PD0325901 shields inductive differentiation stimuli including autocrine fibroblast growth factor-4 (FGF4). CHIR99021 enhances ES cell propagation, which might be due to its exerting a global modulation of the ES cell metabolic and biosynthetic capacity rather than having a direct anti-apoptotic action (Ying et al., 2008) (Fig. 1).

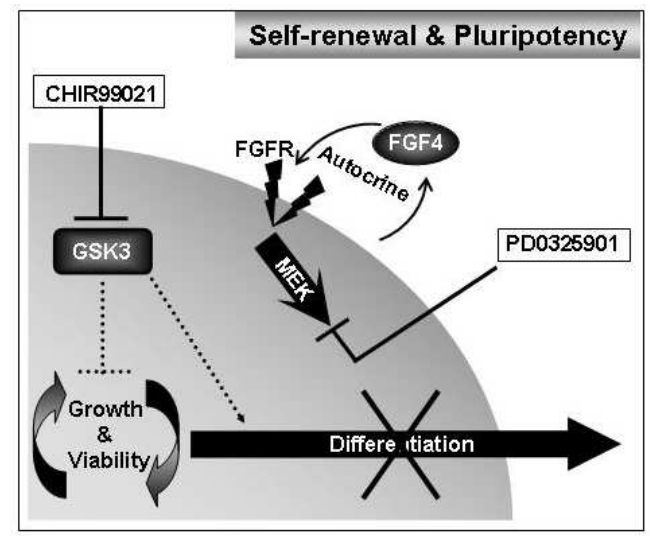

Fig. 1. Mechanism of maintenance of self-renewal and pluripotency

\section{Rat}

The laboratory rat was the first mammalian species domesticated for scientific research, and it has been used as an animal model in physiology, toxicology, nutrition, behavior, immunology, and neoplasia for over 150 years (Jacob, 1999). The physiology is easier to monitor in the rat, and, over time, a volume of data has developed that will take years to be replicated in the mouse. Moreover, in many cases, the physiology is more similar to the corresponding human condition. The size of the animal enhances its use as a disease model, not just because of the ability to perform surgical procedures but also because of the proportional size of important structures in organs that affects both the degree to which the organ is involved in an experimental lesion and the effects of the distance from the drug administration to specific anatomical areas (Iannaccone \& Jacob, 2009).

\subsection{Background of rat ES cells}

After the first mouse ES cell lines were derived 29 years ago (Evans \& Kaufman, 1981; Martin, 1981), many efforts were made to establish rat ES cells. Although a culture medium 
of the mouse ES cells, composed of either serum and LIF or BMP and LIF, has been thought to be available in all species, several groups have failed to establish rat ES cells under similar conditions (Brenin et al., 1997; Buehr et al., 2003; Demers et al., 2007; Fandrich et al., 2002; Vassilieva et al., 2000). We have succeeded in cloning complete rat LIF cDNA and demonstrated that rat LIF has an effect on rat ES cells for the maintenance of a stem-cell phenotype (Takahama et al., 1998). However, their self-renewal potential was temporal in early passages, which may be due to the fact that a similar culture medium to that of mouse ES cells was used.

In 2008, we established new lines of rat ES cells with chimeric contribution by using a devised culture medium and passaging method (Ueda et al., 2008). However, our ES cells could not achieve germline transmission. While a general culture medium for mouse ES cells contains 15 or $20 \%$ FBS, our culture medium contains only $3 \%$ FBS. Details of the method for establishing rat ES cells are described below.

Methods; The rat ES-cell culture medium consisted of DMEM/F12 supplemented with 3\% (vol/vol) FBS, 0.1 mM 2-mercaptoethanol, 1\% nonessential amino acid, 2 mM L-glutamine, 1 $\mathrm{mM}$ sodium pyruvate, antibiotic antimycotic and a nucleoside solution. Frozen embryos obtained at 4.5 days post-coitum of Wistar rats were used for the establishment of ES cells. After removal of the zona pellucida by treating with tyrode's solution, seven to ten embryos were placed on a plate pre-seeded with mitotically inactivated MEFs by a treatment with mytomycin C. After 2 or 3 days, ICM-derived cells were dissociated into clumps mechanically or by exposure to $0.05 \%$ collagenase type IV before transfer onto new MEFs. The propagated cells were routinely passaged every 3-4 days up to 5 passages in the culture medium in the presence of rat LIF at $1000 \mathrm{U} / \mathrm{ml}$ and were then cultured in a medium supplemented with $0,250,500$, or $1000 \mathrm{U} / \mathrm{ml}$ rat LIF.

These rat ES cells showed marker gene expression of ES cells, such as Oct4, Nanog, and SSEA1, and formed embryoid bodies (EBs) after the ES-cell colonies were dissociated by treatment with collagenase IV. Teratomas were formed by subcutaneous, intratesticular or intraperitoneal injection of rat ES cells into SCID mice. Finally, chimeric rats were generated from embryos in which the rat ES cells, cultured in the presence of rat LIF, were injected (Ueda et al., 2008; Kawamata \& Ochiya, 2010a). However, germline transmission was not achieved in the chimeras. Soon after this report, other groups succeeded in establishing authentic ES cells completing germline transmission (Buehr et al., 2008; Li et al., 2008; Hirabayashi et al., 2010). The common technique for maintaining the pluripotency of rat ES cells was to remove the content of fetal bovine serum (FBS) in the culture medium. The two groups suggested that failure in the establishment of authentic rat ES cells over the two past decades was due to the presence of serum (Buehr et al., 2008; Li et al., 2008). Indeed, serum may contain various kinds of nutrient factors as well as differentiation ones for rat ES cells (Kawamata \& Ochiya, 2010a).

The two groups used the $2 \mathrm{i}$, MEK and GSK inhibitors and LIF to overcome the difficulty in the generation of germline-competent rat ES cells (Buehr et al., 2008; Li et al., 2008; Hirabayashi et al., 2010). These studies suggest that cell-signaling inhibitors play a critical role in the maintenance of rat ES cells as well as rat iPS cells.

\subsection{Maintenance of pluripotency and self-renewal by signal inhibitors}

Recent reports suggest that small molecules, which inhibit GSK3, FGF4 through the MAPK pathway, TGF $\beta$, or ROCK signaling, have effects on ES cells for the maintenance of pluripotency and self-renewal. GSK3 is a central node for the negative modulation of a range of anabolic processes and generally acts to suppress the cellular biosynthetic capacity 
(Frame \& Cohen, 2001). GSK3 is inhibited by phosphorylation downstream of growth factors that activate phosphatidyl inositol 3 kinase and Akt. GSK3 is also a key component of the $\beta$-catenin destruction complex, and pharmacological inhibition of GSK3 increases cytoplasmic and nuclear $\beta$-catenin, mimicking canonical Wnt signaling (Ding et al., 2000). The Wnt pathway was assumed to maintain self-renewal of ES cells because the main components of the canonical Wnt pathway were detected in undifferentiated human ES cells (Sato et al., 2003). Indeed, Wnt pathway activation by 6-bromoindirubin-3'-oxime (BIO), a specific pharmacological inhibitor of GSK3 (Meijer et al., 2003), maintained an undifferentiated phenotype in mouse and human ES cells and sustained expression of the pluripotent state-specific transcription factors Oct4, Rex1 and Nanog even in the absence of LIF and MEF (Sato et al., 2004). However, BIO is not highly selective and cross-reacts with cyclin-dependent kinases and other kinases, while CHIR99021 was defined as a more selective inhibitor of GSK3 (Bain et al., 2007; Murray et al., 2004; Zhen et al., 2007). Ying et al. found that the activity of mouse ES cells was reduced by BIO but not by CHIR99021 (Ying et al., 2008). In a report relating to the Wnt pathway, a high-throughput cell-based assay showed that a small molecule IQ-1 allowed for long-term expansion of mouse ES cells and inhibited spontaneous differentiation to prevent $\beta$-catenin from switching coactivator usage from CBP to p300 (Miyabayashi et al., 2007). These reports suggest that the addition of the GSK3 inhibitor or Wnt recombinants in the ES culture medium might be a useful method to continuously propagate undifferentiated ES cells.

FGF signaling is a conserved initiator of vertebrate neural development (Bertrand et al., 2003; Delaune et al., 2005; Launay et al., 1996; Streit et al., 2000; Wilson et al., 2000). Activation of FGF receptors (FGFRs) can initiate transduction via three major intracellular pathways: classical MAPk, phosphatidylinositol 3'-OH kinase (PI3K), and phospholipase C gamma (PLCY), the last two of which can activate protein kinase $C$ proteins (PKCs), which can in turn stimulate ERK1/2 signaling (Schonwasser et al., 1998). A high-throughput chemical screen with a library of 50,000 compounds revealed that the compound SC-1 dually inhibited RasGAP and ERK1, which propagate mouse ES cells in an undifferentiated, pluripotent state even in the absence of MEF, serum and LIF (Chen et al., 2006). Treatment of ES cells with the specific inhibitor for MEK, PD098059 (Burdon et al., 1999), ERK, PD184352 or FGFR, PD173074 and SU5402 also suppressed differentiation of ES cells (Kunath et al., 2007; Stavridis et al., 2007). Furthermore, the majority of Fgf null (Fgf-/-) ES cells (Wilder et al., 1997) or Erk2-/- ES cells were able to retain expression of Oct4 under a differentiation condition without LIF (Kunath et al., 2007). Since Fgf4 mRNA is expressed specifically in ES cells of various animals, FGF4 has been considered as a marker gene of ES cells. On the other hand, these reports suggest that an autoinductive stimulation of the MAPk by FGF4 enhances differentiation of ES cells, especially into neural cells. Thus, the MAPk inhibition might be a key method for suppressing differentiation of ES cells.

An addition of type 1 TGF $\beta$ receptor Alk5 (A-83-01) to the $2 \mathrm{i}$ plus LIF medium enabled the generation of rat-induced pluripotent stem (iPS) cells with chimeric contribution, although germline transmission was not accomplished (Li et al., 2009). Furthermore, a combination of MEK and the ALK5 inhibitors dramatically improved the efficiency of iPS cell generation from human fibroblasts (Lin et al., 2009). These reports indicate that the inhibition of TGF $\beta$ signaling also plays a key role in pluripotency.

Recently, Watanabe et al. found that a ROCK inhibitor, Y-27632, caused human ES cells to block apoptosis after dissociation into single cells by enzymatic treatment. Characteristically, human ES cells need to be subcultured by the bulk-passage method since single ES cells form 
scant colonies. The propagated ES cells cultured by Y-27632 were positive for alkaline phosphatase (ALP), marker genes, such as E-cadherin, Oct4, and SSEA4, and the number of chromosomes was normally kept during a long-term culture (Watanabe et al., 2007). Although the mechanism that allows Y-27632 to form a human ES-cell colony with an undifferentiated state is unknown, the compound was recently used for a single-cell-passaging method.

\subsection{Problems with current rat ES cells}

Although the $2 \mathrm{i}$ plus LIF medium enables the establishment of authentic rat ES cells, the event of germline transmission is rarely achieved. A main reason for the failure is chromosomal instability in rat ES cells during long-term culture. It is known that a chromosomal abnormality is one of the major causes for the loss of germline competence of mouse ES cells (Liu et al., 1997). The germline competence seems to depend on a rat strain for donor ES cell-derivation and host blastocysts. Thus, trials to produce more potent cell lines and to find the optimal combination of rat strains for donor ES cells and host blastocysts remain to be addressed (Buehr et al., 2008; Li et al., 2008).

The rat ES cells cultured in the serum free-2i plus LIF medium are sensitive to the stimuli of genetic manipulation by electroporation and drug-selection, which lead to cell death. To overcome this problem, the temporal use of serum is necessary to protect rat ES cells from the death by such stimuli (Buehr et al., 2008; Li et al., 2008).

\subsection{Importance to establish high-quality rat ES cells}

To produce genetically modified rats, especially in knockout/knockin rats, it is necessary to establish high-quality rat ES cells that retain normal karyotype and pluripotency during long-term culture and should be strongly resistant to stimuli during the process of genetic manipulation. The use of serum is one way to overcome this problem because it generally enables culturing cells to be vigorous.

\section{Establishment of rat ES cells}

The use of serum is a way to overcome the problem of weakness in rat ES cells because it generally enables culturing cells to be vigorous. We addressed suitable combinations of signaling inhibitors based on a culture medium that included 20\% (vol/vol) FBS, DMEM (including $110 \mathrm{mg} / \mathrm{L}$ sodium pyruvate and $200 \mathrm{mM}$ GlutaMAX), $0.1 \mathrm{mM}$ 2mercaptoethanol, 1\% nonessential amino acid stock, and $1 \times$ antibiotic antimycotic. Mitomycin C-treated MEFs resistant to neomycin (Millipore) were used as feeders and maintained in DMEM / 10\% FBS medium with $1 \times$ antibiotic antimycotic.

\subsection{An effect of Rho kinase inhibitor}

We cultured Wistar rat blastocysts in a basic medium containing $20 \%$ FBS, which is generally used for mouse ES cell culture. Although the inner cell mass (ICM) outgrew and showed mouse ES cell-like morphology, an ES cell colony did not appear after dissociation and replating. An addition of the Rho kinase inhibitor Y27632 (10 $\mu \mathrm{M})$ remarkably improved their outgrowth, leading to continuous expansion by performing a clump-passaging method. The clump included 5 to 20 cells. Once the colonies were dissociated into single cells, most of them immediately differentiated. The ES cell-like cells formed domed colonies and were positive for alkaline phosphatase activity and pluripotency markers such as Oct4, Nanog and Sox2 mRNAs (Fig. 2). 


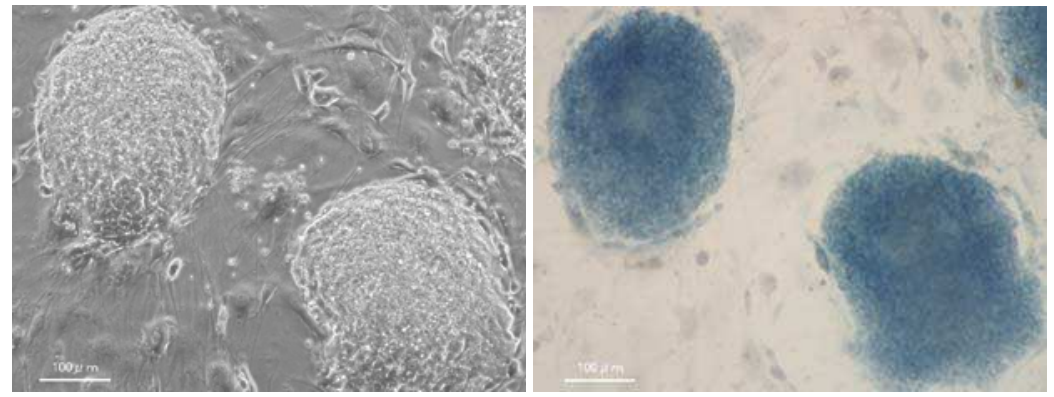

Fig. 2. Colonies cultured in a Y27632-containing medium. At passage 6, the colonies were stained blue, which means that they were positive for alkaline phosphatase activity (right). (scale bar, $100 \mu \mathrm{m}$ )

Generating chimeric animals achieving germline transmission is the gold standard for documenting authentic ES cells. Thus, we tried to produce germline chimeras via microinjection with the rat ES cells into blastocysts. However, the cells did not contribute any tissues or organs. Thus, the cells established by an addition of Y-27632 alone were not authentic ES cells. Details of the blastocyst injection method are described below.

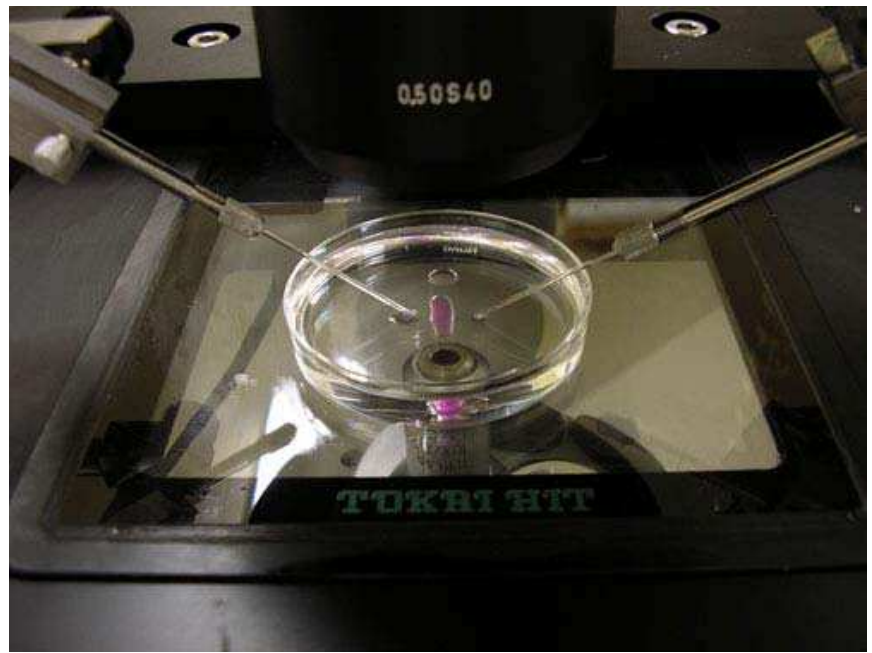

Fig. 3. Device for blastocyst injection with ES cells

Methods; The blastocysts from E4.5 timed-pregnant rats were placed into $500 \quad 1$ of an injection medium, a basal ES cell medium without antibiotic antimycotic, and then were incubated for 2-3 hr. The well-expanded blastocysts were used for microinjection. For ES cell preparation, 10 to 20 domed or floated colonies were picked up by hand-made capillary and treated with Accutase droplet for $5 \mathrm{~min}$ at $37^{\circ} \mathrm{C}$, followed by splitting into single cells in a droplet of the injection medium. The cells were transferred in $500 \mu \mathrm{l}$ of the injection medium and incubated for 30-60 $\mathrm{min}$ at room temperature. After centrifugation, ES cells were transferred into a droplet of the injection medium in mineral oil (SIGMA). Ten to 15 ES cells were injected into each blastocyst (Fig. 3) and incubated at $37^{\circ} \mathrm{C}$ for $3-5 \mathrm{hr}$ in the injection 
medium to allow the embryos to recover. Ten to 20 embryos were then transferred into the uterine horn of each E3.5 pseudopregnant female rat.

\subsection{Four signaling inhibitors are necessary to establish rat ES cells}

We tried various combinations of signaling inhibitors to establish authentic ES cells. Finally, we found that the use of a combination of 4 inhibitors, $10 \mu \mathrm{M} Y-27632,1 \mu \mathrm{M}$ PD0325901, 0.5 $\mu \mathrm{M}$ A-83-01, and $3 \mu \mathrm{M}$ CHIR99021 (termed YPAC) allowed the establishment of authentic rat ES cells. PD0325901, A-83-01, and CHIR99021 are the signaling inhibitors for MEK, Tgf $\beta$, and GSK, respectively.

Cell proliferation of ICM outgrowth was quite rapid under the YPAC condition. The ICMs were picked up using a hand-made needle, followed by extraction of mRNA for the analysis of gene expression. The expression levels of ES cell-marker genes, Oct4, Nanog, Sox2, and Rex1, in ICM cells with YPAC were over 100-fold higher than those without YPAC. Under the YPAC condition, blastocyst outgrowths were observed in 51 samples for all the tested embryos regardless of the strains. The blastocyst strains were derived from Wistar (albino), Long-Evans Agouti (LEA, agouti), or a hybrid of Wistar and LEA (agouti).

A total of Six ES cell lines were established from the blastocysts derived from the three strains. Details of the method are described below.

Methods: After approximately 7 days, the blastocyst outgrowths were cut into pieces and replated under the same YPAC conditions. Emerging ES cell colonies were then dissociated using Accutase and expanded. Established ES cell lines were routinely maintained under MEF-YPAC conditions and passaged every 3-4 days. Floated colonies were also passaged.

Domed colonies were formed from dissociated single cells and could be expanded infinitely. The morphology of their domed colony (Fig. 4) was similar to that of the mouse ES cell colony but slightly different from that of the rat ES cell under the condition of a Y medium (Fig. 2).

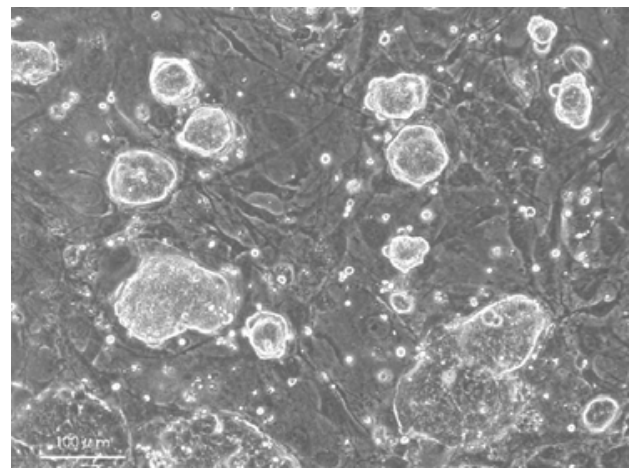

Fig. 4. Colonies cultured in a YPAC-containing medium (passage 3). (scale bar, $100 \mu \mathrm{m}$ )

\subsection{Characteristics of rat ES cells}

The YPAC condition was indispensable for maintenance of the rat ES cells. Y was necessary for adherence on MEF, while PAC was necessary for maintaining their pluripotency. If $Y$ was removed from the YPAC medium, few colonies appeared with proliferating. Thus, $\mathrm{Y}$ is the most important cell-signaling inhibitor in the YPAC medium.

The rat ES cell colonies tend to detach from MEF, differently from mouse ones. The domed colonies are easily detached by pipetting, followed by dissociation and passaging steps. 
Recent reports have indicated that the domed colony possesses a normal karyotype, while the tightly adherent monolayer colony shows chromosomal instability (Kawamata \& Ochiya, 2010; Tong et al., 2010). In fact, our rat ES cells possessed a normal karyotype during long-term culturing due to the passaging of floated colonies.

An alkaline phosphatase activity was positive in the rat ES cells. A microarray analysis showed the rat ES cells kept high levels of marker gene expression such as Oct4, Nanog, Sox2, Rex1, Dppa3, Cdh1, and Tbx1. Immunocytochemistry also showed that Oct4, Nanog, and Sox 2 proteins were expressed in undifferentiated cells.

The classical method to induce ES cell differentiation is to allow the cells to grow in suspension and to form three-dimensional aggregates known as embryoid bodies (EBs) (Keller 1995). Dissociated ES cells were plated into Low-Cell-Binding-Dishes in the basal (without YPAC) medium. EBs were formed from the ES cells at a much lower efficiency compared with their formation from mouse ES cells. The expression of marker genes decreased during the process of EB differentiation. In the presence of PAC, cells aggregated with high efficiency and formed a clear three-dimensional structure. The EBs with PAC at day 7 still sustained high expression levels of the marker genes.

The rat ES cells formed teratomas 34 days after transplantation under the skin of an immunodeficient SCID mouse. A histological examination showed that the teratomas contained all three germ layers, namely, the intestinal epithelium (endoderm), cartilage (mesoderm), and neuronal rosette (ectoderm).

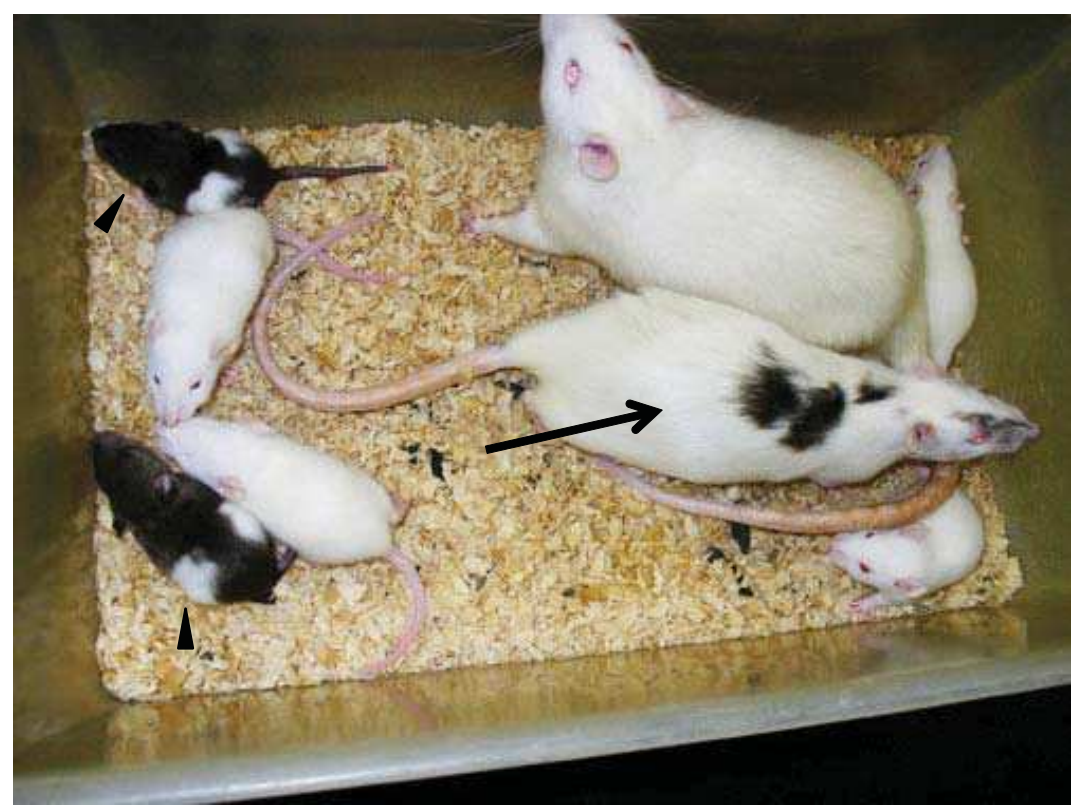

Fig. 5. Germline transmission from chimeric rats. The ES cell line derived from the LEA rat strain was injected into Wistar rat blastocysts, leading to the production of a female chimeric rat with an agouti coat color (arrow). The chimera was mated with a male Wistar rat, and ES cells were transmitted to the next generation with agouti coat color as a Wistar and LEA hybrid strain (arrowheads) 


\subsection{Production of germline chimeras}

We first used a basic ES cell medium without YPAC. However, a coat-color chimera was hardly produced despite the fact that the ES cell line at early passages (6 to 8) was used. Only one male chimera out of 44 pups was obtained, but the chimerism was very sparse.

Next, we added YPAC to the medium during the process of microinjection and blastocyst incubation. This idea was came from the results showing that PAC maintains the pluripotency of cultured cells or EBs. Indeed, PAC addition significantly improved the efficacy to produce chimeric rats. Eight of 23 coat-color chimeras were obtained from the same ES cell line, as reported above, at passage 11 or 12 . The generation of coat-color chimeras was successful in all 6 cell lines. Moreover, after mating with male rats, germline transmission was accomplished in adult female chimeras derived from all the 6 cell lines independently of the rat strain (Fig. 5). This efficiency is considerably higher than that seen in previous reports (Buehr et al., 2008; Li et al., 2008), which might be due to the maintenance of a normal karyotype in the ES cells during long-term culture.

\subsection{Generation of genetically modified rats}

To monitor the ability of stem cells by observing fluorescence, we introduced a transgene in which a Venus protein was expressed by an Oct4 promoter/enhancer. Venus is a mutant protein of yellow fluorescent protein (YFP) (Nagai et al., 2002). The $3.9 \mathrm{~kb}$ Oct4 promoter was obtained from Wistar rat genomic DNA. This region is known to include both the proximal and the distal enhancer, which gives Oct4 expression in the morula, inner cell mass (ICM), epiblast, primordial germ cells (PGCs), and ES cells (Chew et al., 2005). Oct4 mRNA is slightly expressed in somatic stem cells in adult mice (Lengner et al., 2007). Details of the gene introduction are described below.

Methods; For gene introduction, a nucleofector was used. After dissociating ES cells with Accutase, they were washed with PBS (-). Ten $\mu g$ pOct4-Venus transgene linearized by SalI was transfected into 3x $10^{6}$ LEA rat ES cells with the Mouse ES Cell Nucleofector Kit (Amaxa Inc.). The cells were plated on MEFs in the YPAC medium with $2 \%$ matrigel (BD Biosciences). Here, the use of $2 \%$ matrigel is important to maintain the attachment of colonies on MEF. A single colony of a Venus-positive transfectant was picked up using a hand-made capillary and expanded without drug selection.

In this expansion process of each clone, we found that dominant clones showed a Venus expression pattern with heterogeneity, indicating a complex with a strong positive, a weak positive, and a negative. In addition, a small number of clones possessed a Venus expression pattern with homogeneity. A homogeneous expression pattern was also demonstrated by immunocytochemistry for the Oct4 protein. Thus, we injected this clone into Wistar rat blastocysts, leading to the production of chimeric rats. After mating with LEA male rats, Oct4-Venus transgenic rats were delivered from the female chimera via germline transmission. Genotyping for the Oct4-Venus transgene was performed by PCR analysis to amplify the Venus DNA fragment. The transgenic rats were healthy and could produce a new generation. Venus fluorescence was detected in PGCs in fetal gonad at 17.0 days postcoitum (Fig. 6).

We further investigated the Oct4-Venus expression during the outgrowth of ICM and expansion of ES cells. The Venus-positive blastocyst was plated on MEFs in the YPAC medium. ICM cells rapidly expanded, and Venus fluorescence was observed in some of the cells. After replating the ICM by dissociation with Accutase, domed colonies possessing homogeneous expression of Oct4-Venus appeared. The domed colonies could be infinitely 
continued to passage (Fig. 7). This result suggests that we had generated Oct4-Venus transgenic rats, which enabled us to monitor authentic rat ES cells with Venus fluorescence.

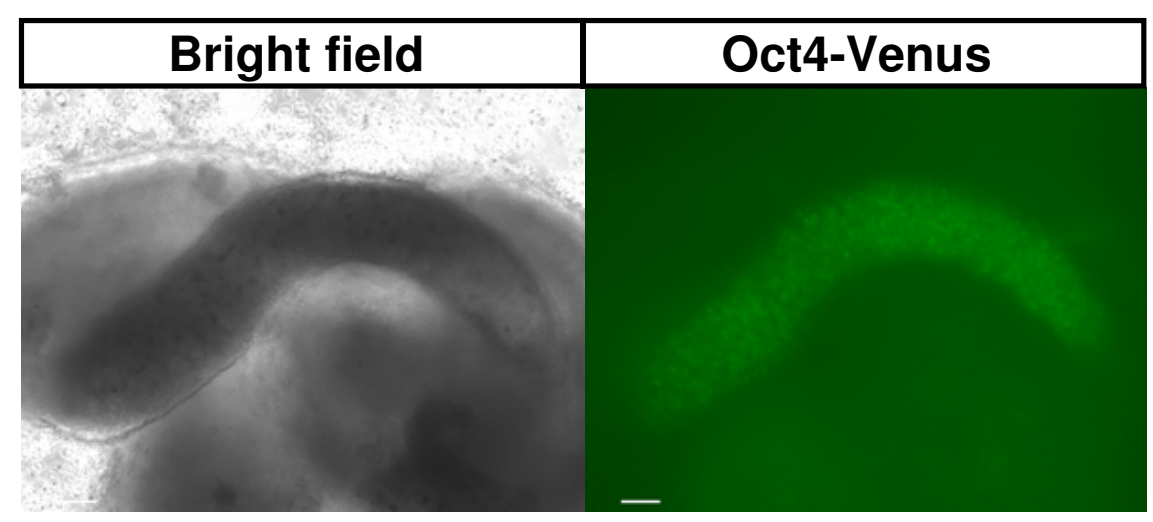

Fig. 6. Oct4-Venus expression in PGCs in fetal gonad. Fetal gonad of Oct4-Venus transgenic female embryo at 16.0 days of gestation was dissected, and Venus fluorescence was observed. (scale bar, $100 \mu \mathrm{m}$ )
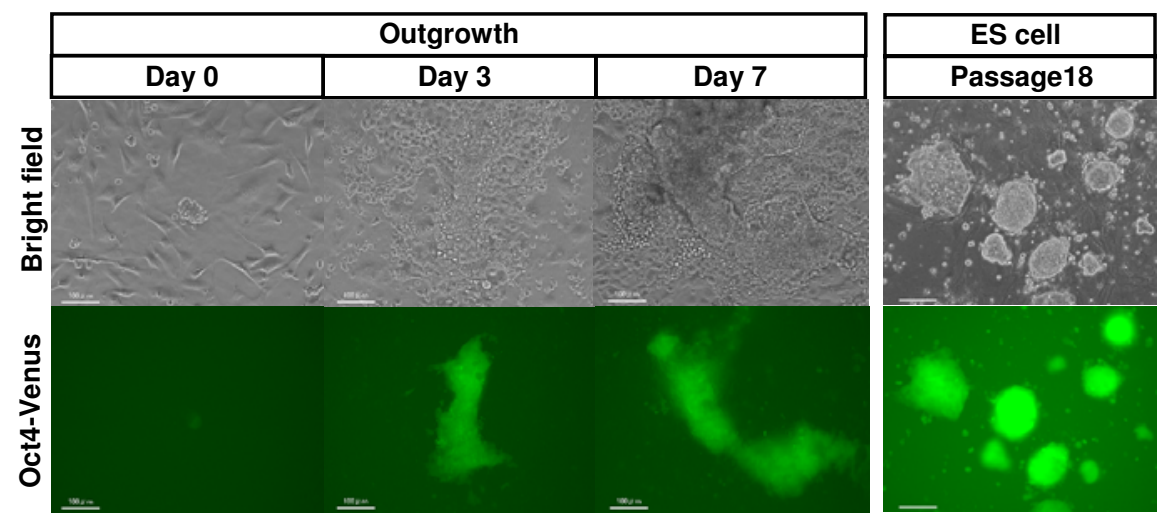

Fig. 7. Oct4-Venus expression during outgrowth of ICM and expansion of ES cells. Blastocyst derived from Oct4-Venus transgenic rats was outgrown on MEFs in the YPAC medium for 7 days. Venus fluorescence was detected in the ICM cells, while it was not detected in differentiated cells. Homogenous Venus fluorescence was observed in ES cells at passage 18. (scale bar, $100 \mu \mathrm{m}$ )

\section{Conclusion}

Our results demonstrated that the use of a combination of serum and cell-signaling inhibitors during outgrowth, cell culture, and blastocyst injection leads to the generation of germline chimeras with extremely high efficiency. Furthermore, we generated genetically modified rats from ES cells. The complete generation of Tg rats might be based on the use of 
a culture medium containing $20 \%$ serum and YPAC, which might strongly protect from cell damage during gene introduction with electric stimuli and maintain pluripotency with a stable karyotype during the cloning and expansion process. Previous works suggested that failure in the establishment of authentic rat ES cells over the two past decades was due to the presence of serum (Buehr et al, 2008; Li et al., 2008). Indeed, serum may contain various kinds of nutrient factors as well as differentiation ones for rat ES cells. Our reason for the present success in the establishment of such significant pluripotent cell lines might be not only the signaling inhibitors shielding ES cells from differentiation but also the utilization of the nutrients in the serum.

Although two groups have reported the establishment of authentic rat ES cells, only one out of several cell lines accomplished germline transmission in each group (Buehr et al., 2008; Li et al., 2008). Thus, trials to produce more potent cell lines and to find the optimal combination of rat strains for donor ES cells, host blastocysts, and recipient foster females remain to be addressed (Buehr et al., 2008; Li et al., 2008). In this study, our YPAC-culture and -injection method overcame the difficulty of completing germline transmission in all the six ES cell lines independently of the rat strain. The YPAC condition will enable the selection of preferable rat strains for the generation of genetically modified rats from ES cells, bringing great advantages to research for strain-specific disease models. We believe that the availability of our rat ES cells and the YPAC-injection technique will also open up a valuable platform for routinely generating knockout/knockin rats, holding out the promise for the generation of new disease models.

\section{Acknowledgements}

This work was supported by a Grant-in-Aid for the Third-Term Comprehensive 10-Year Strategy for Cancer Control.

\section{References}

Bain, J.; Plater, L.; Elliott, M.; Shpiro, N.; Hastie, C.J.; McLauchlan, H.; Klevernic, I.; Arthur, J.S.; Alessi, D.R. \& Cohen, P. (2007). The selectivity of protein kinase inhibitors: a further update. Biochem J, Vol. 408: 297-315.

Bertrand, V.; Hudson, C.; Caillol, D.; Popovici, C. \& Lemaire, P. (2003). Neural tissue in ascidian embryos is induced by FGF9/16/20, acting via a combination of maternal GATA and Ets transcription factors. Cell, Vol. 115: 615-627.

Bradley, A.; Evans, M.; Kaufman, M.H. \& Robertson, E. (1984). Formation of germ-line chimaeras from embryo-derived teratocarcinoma cell lines. Nature, Vol. 309: 255-256.

Brenin, D.; Look, J.; Bader, M.; Hubner, N.; Levan, G. \& Iannaccone, P. (1997). Rat embryonic stem cells: a progress report. Transplant Proc, Vol. 29: 1761-1765.

Buehr, M.; Nichols, J.; Stenhouse, F.; Mountford, P.; Greenhalgh, C.J.; Kantachuvesiri, S.; Brooker, G.; Mullins, J. \& Smith, A.G. (2003). Rapid loss of Oct-4 and pluripotency in cultured rodent blastocysts and derivative cell lines. Biol Reprod, Vol. 68: 222-229.

Buehr, M.; Meek, S.; Blair, K.; Yang, J.; Ure, J.; Silva, J.; McLay, R.; Hall, J.; Ying, Q.L. \& Smith, A. (2008). Capture of authentic embryonic stem cells from rat blastocysts. Cell, Vol. 135: 1287-1298. 
Burdon, T.; Stracey, C.; Chambers, I.; Nichols, J. \& Smith, A. (1999). Suppression of SHP-2 and ERK signalling promotes self-renewal of mouse embryonic stem cells. Dev Biol, Vol. 210: 30-43.

Chen, S.; Do, J.T.; Zhang, Q.; Yao, S.; Yan, F.; Peters, E.C.; Schöler, H.R.; Schultz, P.G. Ding, S. (2006). Self-renewal of embryonic stem cells by a small molecule. Proc Natl Acad Sci U S A, Vol. 103: 17266-17271.

Chew, J.L.; Loh, Y.H.; Zhang, W.; Chen, X.; Tam, W.L.; Yeap, L.S.; Li, P.; Ang, Y.S.; Lim, B.; Robson, P. \& Ng, H.H. (2005). Reciprocal transcriptional regulation of Pou5f1 and Sox2 via the Oct4/Sox2 complex in embryonic stem cells. Mol Cell Biol, Vol. 25: 6031-6046.

Delaune, E.; Lemaire, P. \& Kodjabachian, L. (2005). Neural induction in Xenopus requires early FGF signalling in addition to BMP inhibition. Development, Vol. 132: 299-310.

Demers, S.P.; Yoo, J.G.; Lian, L.; Therrien, J. \& Smith, L.C. (2007). Rat embryonic stem-like (ES-like) cells can contribute to extraembryonic tissues in vivo. Cloning Stem Cells, Vol. 9: 512-522.

Ding, V.W.; Chen, R.H. \& McCormick, F. (2000). Differential regulation of glycogen synthase kinase 3beta by insulin and Wnt signaling. J Biol Chem, Vol. 275: 32475-32481.

Evans, M.J. \& Kaufman, M.H. (1981). Establishment in culture of pluripotential cells from mouse embryos. Nature, Vol. 292: 154-156.

Fandrich, F.; Lin, X.; Chai, G.X.; Schulze, M.; Ganten, D.; Bader, M.; Holle, J.; Huang, D.S.; Parwaresch, R.; Zavazava, N. \& Binas, B. (2002). Preimplantation-stage stem cells induce long-term allogeneic graft acceptance without supplementary host conditioning. Nat Med, Vol. 8: 171-178.

Frame, S. \& Cohen, P. (2001). GSK3 takes centre stage more than 20 years after its discovery. Biochem J, Vol. 359: 1-16.

Hirabayashi, M.; Kato, M.; Kobayashi, T.; Sanbo, M.; Yagi, T.; Hochi, S. \& Nakauchi, H. (2010). Establishment of rat embryonic stem cell lines that can participate in germline chimerae at high efficiency. Mol Reprod Dev, Vol. 77: 94.

Iannaccone, P.M. \& Jacob, H.J. Rats! (2009). Dis Model Mech, Vol. 2: 206-10.

Jacob, H.J. (1999). Functional genomics and rat models. Genome Res, Vol. 9: 1013-1016.

Kawamata, M. \& Ochiya, T. (2010a). Establishment of embryonic stem cells from rat blastocysts. Methods Mol Biol, Vol. 597: 169-177.

Kawamata, M. \& Ochiya, T. (2010b). Generation of genetically modified rats from embryonic stem cells. Proc Natl Acad Sci U S A. Vol. 107: 14223-14228.

Keller, G.M. (1995). In vitro differentiation of embryonic stem cells. Curr Opin Cell Biol, Vol. 7: 862-869.

Kunath, T.; Saba-El-Leil, M. K.; Almousailleakh, M.; Wray, J.; Meloche, S. \& Smith, A. (2007). FGF stimulation of the Erk1/2 signalling cascade triggers transition of pluripotent embryonic stem cells from self-renewal to lineage commitment. Development, Vol. 134: 2895-2902.

Launay, C.; Fromentoux, V.; Shi, D.L. \& Boucaut, J.C. (1996). A truncated FGF receptor blocks neural induction by endogenous Xenopus inducers. Development, Vol. 122: 869-880.

Lengner, C.J.; Camargo, F.D.; Hochedlinger, K.; Welstead, G.G.; Zaidi, S.; Gokhale, S.; Scholer, H.R.; Tomilin, A. \& Jaenisch, R. (2007). Oct4 expression is not required for mouse somatic stem cell self-renewal. Cell Stem Cell, Oct Vol. 11: 403-15.

Li, P.; Tong, C.; Mehrian-Shai, R.; Jia, L.; Wu, N.; Yan, Y.; Maxson, R.E.; Schulze, E.N.; Song, H.; Hsieh, C.L.; Pera, M.F. \& Ying, Q.L. (2008). Germline competent embryonic stem cells derived from rat blastocysts. Cell, Vol. 135: 1299-1310. 
Li, W.; Wei, W.; Zhu, S.; Zhu, J.; Shi, Y.; Lin, T.; Hao, E.; Hayek, A.; Deng, H. \& Ding, S. (2009). Generation of rat and human induced pluripotent stem cells by combining genetic reprogramming and chemical inhibitors. Cell Stem Cell, Vol. 4: 16-19.

Lin, T.; Ambasudhan, R.; Yuan, X.; Li, W.; Hilcove, S.; Abujarour, R.; Lin, X.; Hahm, H.S.; Hao, E.; Hayek, A. \& Ding, S. (2009). Chemical platform for improved induction of human iPSCs. Nat Methods, Vol. 6: 805-808.

Liu, X.; Wu, H.; Loring, J.; Hormuzdi, S.; Disteche, C.M.; Bornstein, P. \& Jaenisch, R. (1997). Trisomy eight in ES cells is a common potential problem in gene targeting and interferes with germ line transmission. Dev Dyn, Vol. 209, 85-91.

Martin, G.R. (1981). Isolation of a pluripotent cell line from early mouse embryos cultured in medium conditioned by teratocarcinoma stem cells. Proc Natl Acad Sci U S A, Vol. 78: 7634-8.

Meijer, L.; Skaltsounis, A.L.; Magiatis, P.; Polychronopoulos, P.; Knockaert, M.; Leost, M.; Ryan, X.P.; Vonica, C.A.; Brivanlou, A.; Dajani, R.; Crovace, C.; Tarricone, C.; Musacchio, A.; Roe, S.M.; Pearl, L. \& Greengard, P. (2003). GSK-3 selective inhibitors derived from Tyrian purple indirubins. Chem Biol, Vol. 10: 1255-1266.

Miyabayashi, T.; Teo, J.L.; Yamamoto, M.; McMillan, M.; Nguyen, C. \& Kahn, M. (2007). Wnt/betacatenin/CBP signaling maintains long-term murine embryonic stem cell pluripotency. Proc Natl Acad Sci U S A, Vol. 104: 5668-5673.

Murray, J.T.; Campbell, D.G.; Morrice, N.; Auld, G.C.; Shpiro, N.; Marquez, R.; Peggie, M.; Bain, J.; Bloomberg, G.B.; Grahammer, F.; Lang, F.; Wulff, P.; Kuhl, D. \& Cohen, P. (2004). Exploita-tion of KESTREL to identify NDRG family members as physiological substrates for SGK1 and GSK3. Biochem J, Vol. 384: 477-488.

Nagai, T.; Ibata, K.; Park, E.S.; Kubota, M.; Mikoshiba, K. \& Miyawaki, A. (2002). A variant of yellow fluorescent protein with fast and efficient maturation for cell-biological applications. Nat Biotechnol, Vol. 20 :87-90.

Rogers, C.S.; Stoltz, D.A.; Meyerholz, D.K.; Ostedgaard, L.S.; Rokhlina, T.; Taft, P.J.; Rogan, M..P; Pezzulo, A.A.; Karp, P.H.; Itani, O.A.; Kabel, A.C.; Wohlford-Lenane, C.L.; Davis, G.J.; Hanfland, R.A.; Smith, T.L.; Samuel, M.; Wax, D.; Murphy, C.N.; Rieke, A.; Whitworth, K.; Uc, A.; Starner, T.D.; Brogden, K.A.; Shilyansky, J.; McCray, P.B. Jr.; Zabner, J.; Prather, R.S. \& Welsh, M.J. (2008). Disruption of the CFTR gene produces a model of cystic fibrosis in newborn pigs. Science, Vol. 321: 1837-1841.

Sato, N.; Sanjuan, I.M.; Heke, M.; Uchida, M.; Naef, F. \& Brivanlou, A.H. (2003). Molecular signature of human embryonic stem cells and its comparison with the mouse. Dev Biol, Vol. 260: 404-413.

Sato, N.; Meijer, L.; Skaltsounis, L.; Greengard, P. \& Brivanlou, A.H. (2004). Maintenance of pluripotency in human and mouse embryonic stem cells through activation of Wnt signaling by a pharmacological GSK-3-specific inhibitor. Nature Med, Vol. 10: 55-63.

Schonwasser, D.C.; Marais, R.M.; Marshall, C.J. \& Parker, P.J. (1998). Activation of the mitogen-activated protein kinase/extracellular signal-regulated kinase pathway by conventional, novel, and atypical protein kinase C isotypes. Mol Cell Biol, Vol. 18: 790-798.

Smith, A.G.; Heath, J.K.; Donaldson, D.D.; Wong, G.G.; Moreau, J.; Stahl, M. \& Rogers, D. (1988). Inhibition of pluripotential embryonic stem cell differentiation by purified polypeptides. Nature, Vol. 336: 688-690. 
Stavridis, M.P.; Lunn, J.S.; Collins, B.J. \& Storey, K.G. (2007). A discrete period of FGFinduced Erk1/2 signalling is required for vertebrate neural specification. Development, Vol. 134: 2889-2894.

Streit, A.; Berliner, A.J.; Papanayotou, C.; Sirulnik, A. \& Stern, C.D. (2000). Initiation of neural induction by FGF signalling before gastrulation. Nature, Vol. 406: 74-78.

Takahama, Y.; Ochiya, T.; Sasaki, H.; Baba-Toriyama, H.; Konishi, H.; Nakano, H. \& Terada, M. (1998). Molecular cloning and functional analysis of cDNA encoding a rat leukemia inhibitory factor: towards generation of pluripotent rat embryonic stem cells. Oncogene, Vol. 16: 3189-3196.

Thomson, J.A. \& Marshall, V.S. (1998). Primate embryonic stem cells. Curr Top Dev Biol, Vol. 38: 133-165.

Ueda, S.; Kawamata, M.; Teratani, T.; Shimizu, T.; Tamai, Y.; Ogawa, H.; Hayashi, K.; Tsuda, H. \& Ochiya, T. (2008). Establishment of rat embryonic stem cells and making of chimera rats. PLoS ONE, Vol. 3: e2800.

Vassilieva, S.; Guan, K.; Pich, U. \& Wobus, A.M. (2000). Establishment of SSEA-1- and Oct-4expressing rat embryonic stem-like cell lines and effects of cytokines of the IL-6 family on clonal growth. Exp Cell Res, Vol. 258: 361-373.

Watanabe, K.; Ueno, M.; Kamiya, D.; Nishiyama, A.; Matsumura, M.; Wataya, T.; Takahashi, J.B.; Nishikawa, S.; Nishikawa, S.; Muguruma, K. \& Sasai, Y. (2007). A ROCK inhibitor permits survival of dissociated human embryonic stem cells. Nat Biotechnol, Vol. 25: 681-686.

Wilder, P.J.; Kelly, D.; Brigman, K.; Peterson, C.L.; Nowling, T.; Gao, Q.S.; McComb, R.D.; Capecchi, M.R. \& Rizzino, A. (1997). Inactivation of the FGF-4 gene in embryonic stem cells alters the growth and/or the survival of their early differentiated progeny. Dev Biol, Vol. 192: 614-629.

Williams, R.L.; Hilton, D.J.; Pease, S.; Willson, T.A.; Stewart, C.L.; Gearing, D.P.; Wagner, E.F.; Metcalf, D.; Nicola, N.A. \& Gough, N.M. (1988). Myeloid leukaemia inhibitory factor maintains the developmental potential of embryonic stem cells. Nature, Vol. 336: 684-687.

Wilson, S.I.; Graziano, E.; Harland, R.; Jessell, T.M. \& Edlund, T. (2000). An early requirement for FGF signalling in the acquisition of neural cell fate in the chick embryo. Curr Biol, Vol. 10: 421-429.

Ying, Q.L.; Nichols, J.; Chambers, I. \& Smith, A. (2003). BMP induction of Id proteins suppresses differentiation and sustains embryonic stem cell self-renewal in collaboration with STAT3. Cell, Vol. 115: 281-292.

Ying, Q.L.; Wray, J.; Nichols, J.; Batlle-Morera, L.; Doble, B.; Woodgett, J.; Cohen, P. \& Smith, A. (2008). The ground state of embryonic stem cell self-renewal. Nature, Vol. 453: 281-292.

Zhen, Y.; Sørensen, V.; Jin, Y.; Suo, Z. \& Wiedłocha, A. (2007). Indirubin-3'-monoxime inhibits autophosphorylation of FGFR1 and stimulates ERK1/2 activity via p38 MAPK. Oncogene, 26: 6372-6385. 


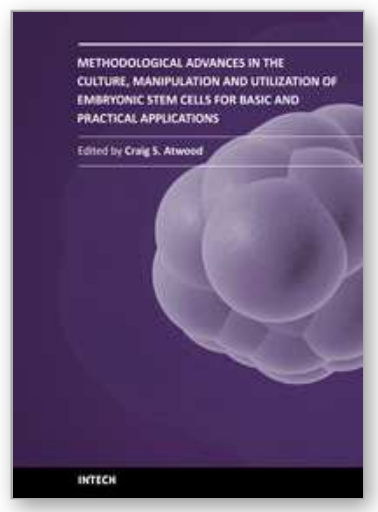

\author{
Methodological Advances in the Culture, Manipulation and \\ Utilization of Embryonic Stem Cells for Basic and Practical \\ Applications \\ Edited by Prof. Craig Atwood
}

ISBN 978-953-307-197-8

Hard cover, 506 pages

Publisher InTech

Published online 26, April, 2011

Published in print edition April, 2011

Pluripotent stem cells have the potential to revolutionise medicine, providing treatment options for a wide range of diseases and conditions that currently lack therapies or cures. This book describes methodological advances in the culture and manipulation of embryonic stem cells that will serve to bring this promise to practice.

\title{
How to reference
}

In order to correctly reference this scholarly work, feel free to copy and paste the following:

Masaki Kawamata and Takahiro Ochiya (2011). Establishment of Embryonic Stem Cells and Generation of Genetically Modified Rats, Methodological Advances in the Culture, Manipulation and Utilization of Embryonic Stem Cells for Basic and Practical Applications, Prof. Craig Atwood (Ed.), ISBN: 978-953-307-197-8, InTech, Available from: http://www.intechopen.com/books/methodological-advances-in-the-culture-manipulation-andutilization-of-embryonic-stem-cells-for-basic-and-practical-applications/establishment-of-embryonic-stem-cellsand-generation-of-genetically-modified-rats

\section{INTECH}

open science | open minds

\section{InTech Europe}

University Campus STeP Ri

Slavka Krautzeka 83/A

51000 Rijeka, Croatia

Phone: +385 (51) 770447

Fax: +385 (51) 686166

www.intechopen.com

\section{InTech China}

Unit 405, Office Block, Hotel Equatorial Shanghai

No.65, Yan An Road (West), Shanghai, 200040, China

中国上海市延安西路65号上海国际贵都大饭店办公楼 405 单元

Phone: +86-21-62489820

Fax: +86-21-62489821 
(C) 2011 The Author(s). Licensee IntechOpen. This chapter is distributed under the terms of the Creative Commons Attribution-NonCommercialShareAlike-3.0 License, which permits use, distribution and reproduction for non-commercial purposes, provided the original is properly cited and derivative works building on this content are distributed under the same license. 